\title{
Posibles razones por las que la Celestina fue considerada anónima durante los siglos XVI-XVIII y creación de Rojas a partir del XIX
}

\author{
Remedios Prieto de la Iglesia \\ IES San Juan Bautista (Madrid) \\ Antonio Sánchez Sánchez-Serrano \\ Exprofesor de la Universidad Complutense
}

\begin{abstract}
Preámbulo
Una de las cuestiones más llamativas en torno a la autoría de la Celestina es la de que durante los siglos XVI, XVII y XVIII fue considerada obra anónima, mientras que a partir de la reaparición de sus ediciones en el siglo XIX tras los años de su prohibición total por la Inquisición, la apreciación de tal autoría dio un giro de 180 grados al ser asignada a Fernando de Rojas por comentaristas, investigadores y casas editoriales (Antonio Sánchez y Remedios Prieto 1991:13-20; Joseph T. Snow 1999-2000, 2001 y 2005-2006).

El objeto del presente trabajo es inferir algunas posibles causas que condujeron a corrientes de opinión tan opuestas basándonos en la constatación de que entre ambas épocas se producen significativos cambios de índole lingüística tales como la grafía de «auctor», que deviene en «autor», la desaparición o pérdida de significado de la primera en los tiempos modernos al identificarse ambos términos y la inexistencia en el Diccionario de Autoridades (y por tanto en los tiempos antiguos) de otros vocablos pertenecientes al campo semántico de la producción de libros, como es el caso de "editor», cuya función se incluía en la de «autor», término que también evolucionó semánticamente en este periodo.

Aplicaremos esta investigación a los paratextos preliminares, que constituyen prácticamente la única documentación coetánea de Rojas disponible para fundamentar interpretaciones sobre la autoría de la Celestina, ${ }^{1}$ pa-

1.- Es verdad que en declaraciones judiciales se nombra a Rojas como el que «compuso a Melibea» o "el que compuso el libro de Celestina» (Antonio Sánchez y Remedios Prieto 1991: 13-16), pero el verbo "componer» no era necesariamente sinónimo de autoría creativa de
\end{abstract}


ratextos que con algunas modificaciones entre las ediciones de la Comedia y la Tragicomedia aparecen en todas ellas, salvo en la de Burgos (1499-1502?) por haber sufrido pérdida de hojas al principio y muy probablemente también al final su único testimonio conservado (Canet 2014 y 2017)

\section{La noción difusa y cambiante del concepto de «autor»}

En los primeros tiempos de la imprenta el concepto de "autor» estaba influido por la tradición del libro manuscrito, que muy frecuentemente ensamblaba textos diversos viniendo a ser fruto de una contribución múltiple. ${ }^{2}$ Así el autor de un libro como preparador de su manuscrito para la estampación resultaba en muchas ocasiones ser más un compilador, adaptador o refundidor de textos preexistentes que un verdadero creador (inventor) de ellos. ${ }^{3}$ Esto era posible porque aún no se había fraguado el concepto moderno de propiedad intelectual, lo que propiciaba que quien era propietario de un manuscrito, bien porque se lo hubieran regalado, vendido, cedido, etc., bien porque se lo hubiera encontrado, se sintiese con derecho para introducir en él cuantas modificaciones juzgara pertinentes antes de entregarlo a la imprenta para su estampación; bastaba con darle el último aspecto para considerarse «autor» del libro. Escribe Pedraza Gracia:

El concepto de autor no es idéntico al actual, adaptadores, comentaristas y traductores son considerados como autores de la obra sin otro requisito que haberle dado el último aspecto y que el editor lo era porque, mediante el sistema que fuese, había adquirido o tenía la propiedad de la obra. Este fenómeno, la propiedad del manuscrito, facultaba de hecho al editor para realizar intervenciones en la obra, traducciones o correcciones. (Pedraza Gracia 2008: 146-147)

Ciertamente, se estaba muy lejos de la noción moderna de autoría, que se va gestando durante los siglos XV-XVIII hasta quedar consolidada en el XIX. Así, Antoine Compagnon analiza las continuidades y cambios de

obras en prosa, según expusimos en trabajos anteriores (1989: 42; 2009: 152) y expondremos en este desde distinto ángulo. Son de la misma opinión otros estudiosos actuales como García Valdecasas (2000: 87-91), Joseph T. Snow (2005-2006: 554-557), Bernaldo de Quirós (2010: 52) o Cantalapiedra (2011), quienes señalan su contigüidad semántica con «arreglar» u "ordenar». Asimismo, Covarrubias aclara en su Tesoro de la Lengua Castellana o Española que componer «es hazer versos [...] También dezimos: Fulano ha compuesto un libro, aunque sea en prosa, por el orden y concierto que lleva en él».

2.- Luciano Canfora en Il copista como autore (2002) señala la dificultad de establecer con certeza la paternidad de una obra pues se disolvía a menudo en una composición plural.

3.- María Jesús Lacarra y José Manuel Cacho Blecua (2012: 260-271) ofrecen una fundamentada reflexión sobre "la construcción de la figura del autor» durante la Edad Media. 
signific do del concepto desde la Antigüedad hasta el siglo xx y llega a la conclusión de que este experimenta un largo proceso evolutivo que se inicia en el Renacimiento con la invención de la imprenta y no se consuma hasta la exaltación romántica de la creatividad. Para Jean-Marc Buigues, todavía en el siglo XviII:

El autor puede ser el que escribe la totalidad de una obra original, su inventor [...].

Pero también puede ser un comentarista, un traductor, un adaptador o el que realiza una compilación, y en la mente de la época dominaba más bien este concepto amplio del autor. [...] Es un autor cualquier individuo bajo cuyo nombre se publica un impreso. (Buigues 2003: 292)

En muchas obras antiguas encontramos también el vocablo «auctor» con significado igualmente variable a lo largo de los tiempos. Oostendorp (1966) distingue tres etapas en su evolución semántica. Durante la Edad Media, se denominaba "auctores» a los escritores del pasado, paganos y cristianos, que habían legado libros redactados en latín y que gozaban de cierta autoridad. En la primera mitad del siglo XV, «auctor» hace referencia tanto a autores ${ }^{4}$ del pasado como contemporáneos, sea cual fuera la lengua que usaran con tal de que respetaran las reglas de la retórica y contribuyeran a la divulgación de la sabiduría. A partir de la segunda mitad del siglo XV puede equivaler a escritor que ha hecho una obra original, a autor en el sentido moderno de la palabra.

Como vemos, ambos vocablos se fueron aproximando en su significado hasta llegar a ser estimados sinónimos o variantes fónico-gráficas carentes de valor semántico. ${ }^{5}$ Esto origina que en algunas transcripciones modernas de textos antiguos en los que aparece la palabra "auctor», se haya suprimido la "c» con el fin de adaptarla a los usos gráficos actuales o de reducir los grupos consonánticos cultos. Sin embargo, aunque parezca existir un uso indiferenciado de ambas formas en numerosos textos antiguos (la vecindad ortográfica y semántica lo propicia), debemos indagar si en la Celestina las palabras «auctor» $\mathrm{y}$ "autor» eran incondicionalmente simples variantes aleatorias o reflejan conceptos distintos. Y si centramos el estudio en los paratextos preliminares que describen la gestación del libro, tal indagación cobra especial interés para abordar el problema de la "autoría", palabra en la que confluyen ambos términos, e intuir las razones que llevaron a los lectores y comentaristas de los siglos XVI-XVIII

4.- La equivocidad del término «autor» aconseja que solo cuando lo empleamos en el sentido actual, es decir, con el significado de inventor/creador de una obra literaria, no lo destaquemos gráficamente. Resaltaremos en versales o cursiva aquellas palabras sobre las que interesa atraer la atención del lector.

5.- Si buscamos sus significados en el Nuevo Tesoro Lexicográfico de la Lengua Española de la RAE, encontramos que todas las ediciones del diccionario académico desde la de 1780 hasta la actual identifican «auctor» con «autor». 
a considerar la Celestina obra anónima y, en cambio, a los estudiosos de los siglos XIX y XX a asignar al Bachiller una autoría creativa. Lógicamente, la cuestión léxica que acabamos de plantear se resuelve mejor si ambos términos se encuentran próximos y en confrontación.

\section{Confrontación de los términos Auctor y Autor en las rúbri- cas editoriales de los paratextos de las ediciones valencianas. Dos referentes distintos}

Tal confrontación se produce en algunas ediciones de la Tragicomedia, ${ }^{6} \mathrm{y}$ entre ellas utilizaremos como referencia para nuestro análisis la impresa en Valencia 1514 por el tipógrafo Juan Joffre ${ }^{7}$ pues en ella se constata una intervención muy directa del humanista, clérigo y catedrático de la Universidad de Valencia Alonso de Proaza, ${ }^{8}$ sin duda el mejor conocedor de la gestación de la Celestina dado que en todas las ediciones figura como "corrector de la impresión» (para nosotros, censor), ${ }^{9}$ según reza la rúbrica que encabeza sus coplas. Tal constatación de su intervención se basa en varios factores:

- Su estancia en Valencia en aquellos años.

- La adición de una estrofa encabezada por el rótulo "Toca cómo se devía la obra llamar Tragicomedia y no Comedia» a las coplas aparecidas bajo su nombre desde la primera edición.

- Es la única edición (excepto las también valencianas de 1518 y 1529, que pueden ser estimadas reediciones de aquella ${ }^{10}$ ) en que Proaza, al dar a conocer «el tiempo y lugar en que la obra primeramente se imprimió acabada", ofrece información sobre la evolución histórica de la Celestina, mientras que en las demás ediciones se determinan solo la fecha y ciudad en que se realizó cada una de ellas, salvo las que llevan la fecha 1502, evidentemente falsa según lo demostró Frederick J. Norton en 1966 (1997: 217-221).

6.- Para el uso de «auctor» y/o "autor» circunscrito a las rúbricas de los paratextos de las ediciones tempranas conservadas de la Celestina, véase el estudio analítico de Antonio Sánchez Sánchez-Serrano y Remedios Prieto de la Iglesia 2011.

7.- El único ejemplar conservado se encuentra en la Biblioteca Nacional de España, signatura R/4870. Existen tres ediciones facsimilares: la de Espasa-Calpe (1975), la del Círculo del Bibliófilo (1977) y la realizada bajo la dirección de Nicasio Salvador y Santiago López-Ríos (1999). Trabajamos sobre estas dado que la mayoría de las ediciones modernas que toman por base o transcriben la edición valenciana sustituyen «auctor» por «autor»; no sucede así en la de Julio Cejador (1913) ni en la de Fernando Cantalapiedra (2000), que mantienen las diferencias.

8.- Son muchos los especialistas que afirman o sugieren que Proaza intervino directamente en esta edición, tales como McPheeters (1961: 189-193), Marciales (1985, I: 231-232), Norton (1997: 214), Salvador Miguel (1999: 14-15), Canet (1999: 35), Patrizia Botta (1999: 24-26) e Infantes (2010: 8).

9.- Véanse Antonio Sánchez y Remedios Prieto 2011: 117-122 y Remedios Prieto 2014.

10.- Sus únicos ejemplares se conservan en la British Library. 
Quizá fuera su deseo de hacer precisiones de carácter histórico sobre la elaboración de la obra lo que condujo a Proaza a dejar constancia, por medio de las rúbricas de los paratextos de su edición, de que en dicha elaboración intervinieron un "auctor» $y$ un «autor» además del «antiguo» autor del manuscrito inacabado y sin firma aludido en la Carta. ${ }^{11}$ El primero de los paratextos, la Carta, va precedido en esta edición de Valencia 1514 y también lógicamente en las valencianas de 1518 y 1529 por el rótulo "El AUCTOR a un su amigo", carta que, en su final, remite a unos "siguientes metros» precedidos por otra rúbrica que reza: «El AUTOR, escusándose de su yerro en esta obra que escrivió, contra sí arguye y compara", en cuyo acróstico se lee «El bachjller Fernando de Roias acabó la Comedia de Calysto y Melybea y fve nascido en la Puebla de Montalván». Si solo atendiéramos a esta remisión, podríamos convenir en que AUCTOR era ya sinónimo o variante fónico-gráfica de AUTOR y que ambos vocablos son aplicables al bachiller Fernando de Rojas.

Sin embargo, profundizando más en el estudio encontramos no pocas contradicciones a tal deducción. En primer lugar, la palabra "acabó» es inadecuada para aludir a una autoría total, o mayoritaria (veinte de sus veintiún autos), que es lo que se deduce de la lectura global de la Carta. Es verdad que "acabar» puede significar también dar los últimos toques a la obra escrita por uno mismo, pero no es este el caso ya que los propios versos acrósticos nos aclaran que se trata de una obra ajena «inventada» por otra persona:
Yo vi en Salamanca la obra presente, movime a acabarla por estas razones: es la primera que estó en vacaciones, la otra, inventarla persona prudente $[\ldots]$

Asimismo, la Carta proporciona otras contradicciones indicativas de que su autor no puede ser la persona mencionada en el acróstico. Por una parte, quien escribió aquella pide disculpas por no dar a conocer su nombre, mientras que el acróstico de los versos ofrece todos los datos de Fernando de Rojas: graduación académica, nombre, apellido y lugar de nacimiento. Por otra parte, en la versión anterior de la Carta, incluida en las ediciones de la Comedia, se hacía una afirmación que permite colegir el carácter manuscrito y la carencia de articulación en autos de la obra enviada por el remitente de la Carta: ${ }^{12}$

11.- Como puede comprobarse, tal denominación no aparece pero su lectura ofrece la evidencia de que efectivamente lo fue.

12.- Hemos defendido el carácter manuscrito de la obra en Antonio Sánchez y Remedios Prieto 1989: 21-26; 1991: 29-32. Asimismo Cantalapiedra 2000, García Valdecasas 2000 y Bernaldo de Quirós 2010, juzgan que la obra en estado manuscrito no estaba articulada en autos. 
E porque conozcáys dónde comiençan mis mal doladas razones y acaban las del antiguo auctor, en la margen hallaréys una cruz y es en fin de la primera cena.

Por el contrario, la alusión al «acabado» de Rojas en los «siguientes metros» se encuentra en la obra ya impresa y dividida en autos. Esta contraposición queda borrada en las ediciones de la Tragicomedia, en las que las palabras de la cita anterior se sustituyen por estas otras:

acordé que todo lo del antiguo autor fuesse sin división en un auto o cena incluso, hasta el segundo auto, donde dize «Hermanos míos», etc.

y no nos resistimos a sospechar que tan drástico arreglo tratara de ocultar lo que dejaba entrever la redacción anterior.

Queda sin embargo en pie la contradicción de que el "auctor» de la Carta remite a los "siguientes metros» y que estos llevan el nombre de Rojas. Ya argumentamos en otros trabajos (1985,1989, 1991, 2009, 2011, 2017) que tales metros existieron realmente y que en ellos no se incluía el nombre del Bachiller: se trata de las estrofas 4, 5, 6 y 7 de la serie total en cuyo acróstico se lee escuetamente SACABÓ LA COMEDIA DE CALISTO y MeLIBEA y sus versos encierran un contenido temático pleno e independiente del de las estrofas que preceden y siguen con los datos identificativos del Bachiller en sus acrósticos, las cuales, desde nuestra perspectiva, fueron añadidas tiempo después por otra persona cuando se preparó el manuscrito con el fin de llevarlo a la imprenta para su estampación

\section{Los significados de Auctor y Autor y sus afinidades con los de otros términos. Signos para inferir la anonimia de la obra y la labor de Rojas}

En aparente discrepancia con lo expuesto en el apartado 1 en relación con las antiguas diferencias entre "auctor» $\mathrm{y}$ "autor» basadas en cierto modo en la auctoritas o en la originalidad de la obra, no podemos eludir la obviedad de que también el "auctor» de la Carta confiesa haber continuado una obra ajena, lo que añade una nueva e importante dificultad, pues en este caso la utilización de dichos términos no queda justificada por tales diferencias.

No obstante, el Diccionario de Autoridades (DA) nos proporciona los datos lingüísticos necesarios para resolver el dilema. Es verdad que su primer tomo fue publicado en 1726 y el sexto y último en 1739 , es decir, que sus definiciones vieron la luz entre 226 y 239 años después de la probable 
primera edición de la Celestina, Toledo 1500;13 pero el hecho de que muchas de sus acepciones hayan sido ilustradas con citas de autoridad nos permite precisar con bastante exactitud si tenían plena vigencia cuando se prepararon las ediciones valencianas. En su primer tomo se registra la siguiente definición de «auctor»

Auctor. Término forense antiguo, y corresponde al que vende alguna cosa, o traspassa alguna acción, u derecho a otro. Es voz antiquada, y tomada del latino Auctor. Lat. Venditor. Hug. Cels. Repert. en esta palabra. Auctor es aquel de quien alguno tiene cosa alguna, o derecho. ${ }^{14}$

La calificación de "voz antiquada» nos incita a indagar la época de su plena vigencia, para lo que la cita de autoridad resulta inestimable. Hugo de Celso fue autor del diccionario Las leyes de todos los reynos de Castilla, abreviadas y reduzidas en forma de repertorio decisivo por la orden del $A B C$, publicado en 1538. Esta obra estaba incluida en los «libros de leyes» que poseyó Fernando de Rojas, según se consigna en el inventario de sus bienes realizado a su muerte (Valle Lersundi 1929: 382-383). Por tanto, en 1514, fecha en que aparece delante de la Carta la rúbrica que comentamos, tal concepto estaría en pleno uso dado que los 24 años de diferencia entre ambas ediciones no son significativos respecto a la evolución semántica de las palabras.

En cambio, como en nuestros tiempos la palabra «auctor» es una simple reliquia del pasado que permanece en las ediciones del diccionario de la RAE (DRAE) solo como recuerdo histórico y con una acepción que no se corresponde con la arriba transcrita del $D A$ pues lo iguala a "autor», la interpretación de su significado nos exige rastrear en los diccionarios la existencia de palabras de uso actual equivalentes al antiguo vocablo «auctor». En el mismo DA y en los posteriores de la Real Academia Española encontramos las siguientes:

Cediente. part. activo del verbo Ceder. Ceder. Dar, alargar, transferir, o traspassar a otro alguna cosa propria, o a que se tiene esperanza, acción, u derecho. (DA)

Cedente. Part. act. de Ceder. El que cede. Ceder. Dar, transferir, traspasar a otro alguna cosa, acción o derecho. (DRAE desde la edición de 1817 hasta la actual)

13.- Postulamos la condición de princeps de la edición de Toledo 1500 en nuestro artículo de 2011:117-122. También puede verse una defensa de la precedencia de la toledana de Hagenbach sobre la burgalesa de Fadrique de Basilea en José Luis Canet 2014 y 2017, Antonio Sánchez 2014: 125-127, 138-140 y Remedios Prieto 2014: 120-121.

14.- Du Cange, en su Glossarium ad Scriptores Mediae et Infimae Latinitatis (1678), define de forma similar el término auctor: «Auctor, apud Latinos Scriptores et IC. dicitur dominus rei, vel venditor, qui rem vendit, dominumque illius habere se profitetur, probatque.» 
$\mathrm{Si}$, como acabamos de ver, AUCTOR era el que «traspassa alguna acción, u derecho a otro» Y CEDER, según los diccionarios de la RAE, es «traspasar a otro alguna cosa, acción o derecho", la identidad semántica entre "auctor» $\mathrm{y}$ «cedente» no puede ser más absoluta. Por lo tanto, al leer en la actualidad esta rúbrica deberíamos traducirla mentalmente como «El CEDENTE a un su amigo", que es el sentido que a través del término "auctor» percibirían en la rúbrica los antiguos lectores cultos de las ediciones valencianas.

Desde esta perspectiva, el significado que cabe darle a la Carta es este: un escritor encuentra una obra incompleta y sin firma, es decir, el manuscrito de un autor desconocido, adquiriendo así sus derechos sobre él, lo reescribe completándolo a su gusto y lo remite "a un su amigo», traspasándole así sus derechos a lo encontrado y los de su propia acción, aclarando que lo hace "para pagar las muchas mercedes de vuestra libre liberalidad recibidas».

$\mathrm{Si}$, como señalábamos páginas arriba, la obra enviada era manuscrita y el remitente no quiere que conste su nombre:

Y pues él [el autor del manuscrito hallado] [...] celó su nombre, no me culpéys si en el fin baxo que le pongo no espressare el mío,

queda respaldada nuestra deducción anterior de que el «auctor» de la Carta no puede ser identificado con el «autor» mencionado en el acróstico

Esta conclusión nos obliga a profundizar en el significado de «autor» cuando vieron la luz las ediciones tempranas de la Celestina. El DA registra:

Autor. El que inventa, discurre, hace y da principio a alguna cosa. [...] Comúnmente se llama el que escribe libros, y compone y saca a luz otras obras literarias.

La primera parte de la definición es de carácter general y no se refiere específicamente al mundo de los libros; la segunda sí, y los términos enfatizados sugieren la posibilidad de que la acción del «autor» pueda consistir $^{15}$ en la preparación para la publicación de "otras obras" ya existentes, según se desprende de las palabras y frases de esa segunda parte:

EsCRIBIR. [...] Por antonomasia se entiende escribir con la pluma en papel. [...] Vale también componer libros, discursos, historias y otras obras, y dexarlas escritas o impresas. $(D A)$

En esta segunda acepción de «escribir» vinculada a la palabra «autor» encontramos una muestra de la relación más o menos directa entre «autor» $\mathrm{y}$ «componer» observable en muchas obras, entre ellas en el Íncipit de la Celestina:

15.- Empleamos los términos «pueda consistir» porque no debemos dejar de tener en cuenta que el autor podía también escribir una obra original, completamente inventada por él. 
Síguese la Comedia o Tragicomedia de Calisto y Melibea, compuesta en reprehensión de los locos enamorados [...]

Esto nos induce a prestar atención a un significado de COMPONER acorde con la práctica de producción de textos y a otras palabras que establezcan equivalencia semántica con este verbo:

COMPONER. Aderezar, concertar y poner en orden lo que está descompuesto y desordenado. (DA)

Aderezar. Componer, adornar, y pulir alguna cosa. $(D A)$

CONCERTAR. Componer, ordenar, adornar alguna cosa. (DA)

palabras que reflejan el comentario de Covarrubias reproducido en la nota 1 y que sugieren los trabajos necesarios para arreglar el texto de una obra manuscrita con el fin de entregarla a la imprenta. Y esto se aviene con la definición de $D A$ para:

Componer un libro u otra cosa. Hacerla, formarla de nuevo, y de invención propria.

Es verdad que la expresión «formarla de nuevo» resulta algo ambigua, por lo que para desambiguarla hemos recurrido al encadenamiento de las acepciones que proporciona el $D A$ en las siguientes entradas:

De nuevo. Modo adverbial que vale lo mismo que Nuevamente.

NueVAmente. De poco tiempo a esta parte, o con novedad.

NovedAD. Se toma también por la mutación de las cosas, que por lo común tienen estado fixo, o se creía que le debían tener.

Así llegamos a la conclusión de que la expresión «formarla de nuevo» guarda afinidad semántica con "formarla con mutación», en definitiva, «darle nueva forma».

Los sintagmas «nueva forma» o "forma diferente» aplicados al estado final de obras literarias se encuentran en acepciones de los diccionarios académicos para palabras cuyos significados no dejan lugar a dudas

Refundir. Dar nueva forma y disposición a una obra de ingenio, como una comedia, un discurso, etc. con el fin de mejorarlo. (DRAE desde 1837)

ADAPTAR. Modificar una obra científica, literaria, musical para darle una forma diferente del original. (DRAE desde1983)

Vemos así que las palabras que el $D A$ y otros posteriores de la RAE identifican o relacionan con COMPONER, vinculando este término a la auto- 
ría de libros, son: «aderezar», "concertar, «ordenar», «adornar», «dar nueva forma», "refundir» $y$ "adaptar», es decir, con palabras que implican una actuación sobre algo ya existente. ${ }^{16}$

Un testimonio valioso en torno a la relación en fechas próximas a 1514 de estos conceptos de AUTOR Y COMPONER, así como del significado atribuible a este último vocablo, es el de Francisco Delicado, quien en su proemio a la edición del Amadís de Gaula de Venecia 1533 se refiere a Garci Rodríguez (u Ordóñez) de Montalvo denominándole «autor del libro» y "componedor» por su labor de "enmendar» y "corregir» textos ajenos, según declara el mismo Montalvo en el Prólogo y especifica el Íncipit, ${ }^{17} \mathrm{O}$ dicho de otra manera, por su labor de refundir. ${ }^{18}$

Si volvemos ahora a la acepción de AUTOR del $D A$, nos fijamos en su última frase: "[el que] saca a luz otras obras literarias", y, pese a que nos parezca obvio, indagamos el significado del sintagma «sacar a luz» en el mismo diccionario, lo encontramos así en la voz "luz»:

\author{
SACAR A LUZ. Dar a la estampa, imprimir y publicar algún \\ libro u otra cosa,
}

16.- Estos significados de «componer» equivalentes a realizar algo con o sobre textos previamente existentes, cobran realidad tanto en la época del libro manuscrito como en la de la imprenta. Para los tiempos del libro manuscrito valgan dos casos representativos: el de Alfonso X y el del Cancionero colectivo de Juan Alfonso de Baena. Alfonso X, en el prólogo de la Estoria de España, emplea el término "componer» para la labor de ayuntar, compilar, ordenar y concertar fuentes para "componer su libro». Y en el Cancionero se lee: "El qual dicho libro [...] fiso e ordenó e compusso e acopiló el indino Johan Alfonso de Baena» (Azáceta 1966: I: 4), y más adelante: "Este decir fizo Johan Alfonso de Baena componedor d'este libro» (Azáceta 1966: I: 87). En cuanto a los tiempos de la imprenta, he aquí algunos ejemplos: Breve tractado compuesto por Johan de Flores [...], la invención del qual es sobre la Fiometa (c. 1495); Carro de dos vidas [...] compuesto por Gómez García [...] traído del latín en romance de muchos libros y partes de la Sagrada Escritura (1500); y Orthographía castellana [...] Compuesta y recopilada de diversos autores por el P. Francisco Pérez de Nájera [...] (1604).

17.- Escribe Francisco Delicado: «En aquel glorioso siglo quando el muy sabido AUTOR DEL PRESENTE LIBRO dexó en memoria no solamente la vida, fort[al]eza, gloria, esfuerço y fechos animosos [...].Esto todo nos mostró en esta tan sabrosa obra el sabido COMPONEDOR mostrando en Amadís de Gaula todas aquellas virtudes [...] que el mismo AUTOR DeL LiBro los puso en diversos vocablos [...] ¡Quán maravillosamente este AUTOR nos pintó este cavallero Amadís de Gaula!».

En el Prólogo Montalvo afirma que corrigió los «tres libros del Amadís, que por falta de los malos scriptores, o componedores, muy corruptos y viciosos se leían, y trasladando y enmendando el libro cuarto con las Sergas de Esplandián su hijo...» (Por la transcripción Cacho Blecua 2008: I: 224). Y en el Íncipit se lee: «Aquí comiença el primero libro del esforçado y virtuoso cavallero Amadís [...] el cual fue corregido y enmendado por el honrado y virtuoso cavallero Garci-Rodríguez de Montalvo, regidor de la noble villa de Medina del Campo, y corregióle de los antiguos originales que estavan corruptos y mal compuestos en antiguo estilo, por falta de los diferentes y malos escriptores [...]” (Por la transcripción, Cacho Blecua 2008: I: 224225, énfasis añadido).

18.- Para la labor de refundición de Montalvo, puede verse, por ejemplo, Cacho Blecua (2008: 57-82) o el estudio de Avalle-Arce (1990). 
definición que coincide en sus términos con la que el mismo diccionario ofrece para:

EDición. Publicación e impresión de algún libro o escrito.

Así pues, según el $D A$, la edición era tarea propia del «autor» y esta realidad queda confirmada por la ausencia en dicho diccionario de los vocablos EDITOR y EDITAR, que no se incluyen en los diccionarios académicos hasta 1791 y 1899 respectivamente:

EDitor. El que saca a luz, o publica alguna obra ajena y cuida de su impresión.

EDITAR. Publicar por medio de la imprenta una obra, periódico, folleto, etc.

En consecuencia, si traducimos a vocablos actuales las rúbricas de la Carta y de los versos acrósticos, cabría expresarlas así:

\section{El CEDENTE a un su amigo}

El EDITOR, excusándose de su yerro en esta obra que escribió [COMPUSO, ENMENDÓ, REFUNDIó], contra sí arguye

$$
\text { y compara }
$$

Hemos empleado el verbo 'traducir' para subrayar la circunstancia de que los vocablos que permiten llegar a estas identificaciones no son comunes a los tiempos en que se publicaron las ediciones valencianas y a los actuales. Ya quedó claro que en la actualidad no existe la palabra AUCTOR y no sabemos de nadie que, salvo nosotros (2009 y 2011), haya considerado su antiguo significado como "término forense antiguo». Por el contrario, los antiguos no conocían el vocablo EDITOR, por lo que en su lugar utilizaban AUTOR.

La identificación de AUCTOR con CEDENTE y AUTOR con EDITOR se percibe nítidamente en el título que lleva la portada de la segunda edición del Cancionero general de Hernando del Castillo, ${ }^{19}$ que vio la luz en la misma ciudad (Valencia) y en el mismo año (1514) que la Tragicomedia de Calisto y Melibea que sirve de base para nuestros comentarios:

Cancionero general de muchos y diversos AUCTORES, otra vez impresso, emendado y corregido por el mismo AUTOR [...]

título del que debemos sacar tres conclusiones que refuerzan y fundamentan otras extraídas anteriormente sobre los significados de AUCTOR y AUTOR:

1. Que el concepto de AUCTOR como «término forense» y equivalente a CEDENTE se utilizaba en el ámbito de la literatura en los primeros tiem-

19.- Reproducida en facsímil por Rodríguez Moñino (1958: 55) y transcrita por González Cuenca (2004, IV: 3). 
pos de la imprenta ya que los "muchos y diversos auctores» tendrían plenos derechos sobre sus obras originales y las habrían cedido (o tolerado su uso) para la publicación, por supuesto con sus nombres.

2. Que entre las funciones del AUTOR se incluían las de "enmendar»y "corregir» así como la de «imprimir» (naturalmente a mano, es decir, "escribirlo» para la edición y previamente para el censor).

3. Que Alonso de Proaza tenía que conocer perfectamente el significado de los términos «auctor» $\mathrm{y}$ "autor», dado que era uno de los AUCTORES de los poemas integrantes del Cancionero general, cuyo AUTOR era Hernando del Castillo. De donde se infiere que los utilizó a plena conciencia en las rúbricas de su edición de la Tragicomedia de Valencia $1514 .^{20}$

Y para terminar. Si, en los paratextos preliminares de la Celestina, el anónimo CEDENTE viene a decir que traspasa sus derechos a «un su amigo» y quien utiliza esos derechos y EDITA una obra en la que aparece su nombre aunque solo como "acabador» es Fernando de Rojas, deberemos colegir que fue él precisamente ese "amigo» destinatario de la Carta y, por tanto, el que "enmendó», "corrigió», "compuso», "refundió»y "sacó a luz» la obra manuscrita anónima remitida con aquella.

\section{La interpretación de la autoría de la Celestina a través de los siglos}

Que la Celestina fue conceptuada obra anónima hasta bien entrado el siglo XIX es un hecho constatado con precisión y amplitud por Joseph $\mathrm{T}$. Snow (1999-2000, 2001 y 2005-2006).

En efecto, en la portada de las ediciones antiguas no consta el nombre de Fernando de Rojas, solo se encuentra en los versos acrósticos que dejan bien claro el carácter limitado de su aportación: haber "acabado» la Comedia de Calisto y Melibea. Y si tenemos en cuenta que el AUctor de la Carta declara también haber dado fin a una obra ajena, Rojas sería solo, según estos paratextos preliminares, el tercero que aportó algo al texto que apareció impreso, lo que resultaba insuficiente para otorgarle la autoría real. En los ambientes literarios contemporáneos de Rojas ni en las dos centurias posteriores le consideraron creador de la Celestina, ni los moralistas le nombran cuando tratan de la obra, ni tampoco cita su nombre ninguno de los continuadores de la Tragicomedia ni se anota en los inventarios de libreros, bibliotecas y particulares que sí registran el título.

20.- La definición de «auctor» que proporciona Hugo de Celso: «Auctor es aquel de quien alguno tiene cosa alguna, o derecho", hace que pueda ser aplicada tanto a poetas vivos como a difuntos, como eran ya algunos cuyas composiciones incluye Hernando del Castillo en su Cancionero. 
El Diccionario de Autoridades deja una interesante prueba de ese carácter anónimo atribuido a la Celestina. Al principio de cada uno de sus seis tomos se coloca una "Explicación de las abreviaturas de los nombres de autores y obras que van citados» en él, lo que efectivamente se lleva a cabo con exactitud, por orden alfabético de autores; pero cuando llega a la Celestina, solo se hace referencia a sus protagonistas: Calixto y Melibea en el primer tomo, Calisto y Melibea en el segundo, y al título completo de la obra, Tragicomedia de Calisto y Melibea, en los cuatro restantes. ${ }^{21}$ Este hecho es un reflejo importante de la consideración de la Celestina como obra anónima, propia de aquella época: en primer lugar por tratarse de una publicación de la Real Academia Española — nada menos que su primer diccionario-y después por el profundo conocimiento de la Tragicomedia que acreditaban los académicos al encontrar en ella muchísimas ilustraciones para las acepciones de sus vocablos. ${ }^{22}$ Es verdad que en el primer tomo se incluye una «Lista de los Autores elegidos por la Real Academia Española, para el uso de las voces y modos de hablar [...]» y que en ella sí se recoge el nombre de Rojas; sin embargo, la lectura de la cita nos induce a pensar que quien la confeccionó - no necesariamente un investigador - se limitó a ojear los libros acumulados al efecto por la Real Academia para tomar de ellos sus datos, redactando así su información sobre el autor de la Celestina: «Rodrigo Cota, o sea el Bachiller Fernando de Roxas: Calixto y Melibea, o Celestina» (pág. lxxxv).

Ya a finales del siglo XviII, un año antes de que la Celestina quedara proscrita definitivamente en 1792 y no muchos años después de la publicación del Diccionario de Autoridades, la Inquisición encargó a dos censores, los doctores Diego de Mello y Francisco Domingo de Esnarrizaga, la revisión de la Celestina y ambos atribuyen a Fernando de Rojas la misma función que realizaron tanto Hernando del Castillo en la segunda edición de su Cancionero general como Montalvo en el Amadís de Gaula: la de «corregir y enmendar». He aquí las palabras del Dr. Mello y del Dr. Esnarrizaga sucesivamente:
[...] he visto el Libro intitulado tragi-Comedia de Calisto y Melibea, correjido y enmendado por el bachiller Dn. Fer- nando de Roxas, natural de la Puebla de Montalván [...] (Por la transcripción, Luis Rubio 1985: 291)
[...] he leýdo y rehevisto un libro intitulado trajicomedia de Calisto y Melibea, correjida y enmendada por el Bachi-

21.- Esta "Explicación» del Diccionario de Autoridades da el mismo tratamiento de anonimia a la Historia de Amadis de Gaula, cuyas referencias se indican en los tomos 4, 5 y 6, y ya hemos visto en el apartado 3 en qué consistió la labor de su «autor» Garci Rodríguez (u Ordóñez) de Montalvo.

22.- Ejemplos: abatir y abatirse, agarrochado, allende, allí, confeccionar, desfucia, encandilado, ficto, impervio, etc. 
ller D. Fernando de Rojas natural de la Puebla de Montalbán [...] (Por la transcripción, Luis Rubio 1985: 291)23

En definitiva, a finales del el siglo xviII Fernando de Rojas no era aún reconocido como autor-creador de la Celestina, solo se le atribuía haberla "corregido y enmendado».

Sin embargo, al volverse a editar la Tragicomedia a partir de la tercera década del siglo XIX, el nombre de Fernando de Rojas se va estampando progresivamente en la portada y/o en la página del título. Así, en la edición de Tomás Gorchs (1841) se lee: La Celestina o Tragi-comedia de Calixto y Melibea. Empezada por Juan de Mena y por Rodrigo Cota, y concluida por Fernando de Rojas.

Desde entonces y especialmente tras los estudios de Menéndez Pelayo (1895), la Celestina comenzó a ser atribuida a Fernando de Rojas incluso en su totalidad, iniciándose así una etapa editorial en la que, en contraposición a las ediciones anteriores a la proscripción, el nombre de Fernando de Rojas irá cobrando protagonismo en la cubierta y portada del libro a medida que avanzan los siglos XIX y XX hasta hacerse práctica de uso universal, según ha documentado Joseph T. Snow (1999-2000: 152, 153, 165; 2005-2006: 539, 540, 554, 557). Asimismo, frente a los escritores de los siglos pasados que nunca citaban a Rojas como autor-creador de la Celestina, la mayoría de la crítica del siglo xx y en menor proporción la del siglo XXI, parten de la premisa de que Fernando de Rojas lo fue total o mayoritariamente..$^{24}$

¿A qué puede deberse este cambio radical de apreciación? Cuando después de casi doscientos años de sequía lectora y editorial, a causa de la evolución del gusto lector operado en el público del Barroco y Neoclasicismo y de la introducción sucesiva de la Celestina en los Indices (Donatella Gagliardi 2007) y posterior proscripción total, vuelve a editarse en el

23.- También pueden verse estas transcripciones en Joseph T. Snow (1997: 267) y Donatella Gagliardi (2007: 78-79).

24.- La crítica asume posiciones diversas. Estiman, entre otros críticos, que el Bachiller es autor único de los veintiún autos de la Tragicomedia: Blanco-White (1824), González Aguejas (1894), Wolf (1895), Menéndez Pelayo (1895 y 1905-1915), Valera (1900), Asensio (1952), Giulia Adinolfi (1954), Ruiz Ramón (1974) y Emilio de Miguel (1996). Entre los que juzgan que Rojas es autor único de los 16 autos de la Comedia, citaremos a Cejador (1913), quien atribuye a Proaza la Carta, los versos acrósticos y los aditamentos e incrementos que dieron lugar a la Tragicomedia. Señalan que hubo un autor del Auto I, que Rojas lo fue de los quince que completan las ediciones de la Comedia, y que hubo además un «interpolador» artífice del Tratado de Centurio y de los incrementos, modificaciones y supresiones en los primitivos dieciséis: House, Mulroney y Probst (1924), que ven en Proaza al «interpolador», y Garci-Gómez (1993). La teoría más en vigor en el siglo xx y sigue siéndolo en la actualidad es la que atribuye a Rojas la redacción de veinte de los 21 autos de la Tragicomedia, siendo defendida o admitida por Bonilla y San Martín (1904), Castro Guisasola (1924), Ruth Davis (1929), Menéndez Pidal (1950), Criado de Val (1955), Riquer (1957), Bataillon (1961), Gilman (1974), Ayllón (1984), Severin (1989), Nicasio Salvador (1991), Lobera et alii (2000 y 2011), Russell (2001), etc. y por numerosos manuales y libros de texto escolares. 
siglo xIx, las circunstancias de su recepción son otras. Ha cambiado la noción de autoría y en el contexto lingüístico se han borrado las diferencias semánticas entre los vocablos "auctor» $y$ "autor», aquel ha desaparecido en el uso y este ha dejado de ser la persona que "compone y saca a luz otras obras literarias» (DA) para devenir en la "persona que ha hecho una obra científica, literaria o artística» (DRAE desde 1899), y han surgido nuevos vocablos relativos al mundo del libro que no existían en la época de las ediciones tempranas.

Además, la prohibición de la Inquisición dio lugar a la destrucción de innumerables ejemplares y a la ocultación o envío al extranjero de otros. Debe considerarse especialmente la edición de Valencia 1514, de la que en la actualidad queda solo el ejemplar de la Biblioteca Nacional de España, y sus reediciones también valencianas de 1518 y 1529, cuyos únicos ejemplares se conservan en la British Library. Si los originales de estas ediciones no estaban al alcance de algunos de los eruditos que abrieron el camino de los estudios celestinescos en el siglo XIX, era imposible que repararan en la contraposición entre «auctor» para la Carta y «autor» para los versos acrósticos, pero aunque sí pudieran consultar esas ediciones, ${ }^{25}$ los diccionarios de la RAE proclamaban ya la identidad en el significado de ambos términos. Además, la ausencia en los diccionarios de la RAE del significado forense de AUCTOR les impediría equipararlo con CEDENTE, lo que sí habían podido hacer los antiguos lectores y comentaristas; en cambio estos no conocían la palabra EDITOR por lo que en su lugar utilizaban AUTOR, algo inaceptable en los tiempos actuales salvo cuando un autor edita su propia obra.

Es más, la única frase que, por aludir a la colocación de una cruz en el margen que señalaba el "fin de la primera cena», permite inferir que quien redactó la Carta envió "a un su amigo» una obra manuscrita y no articulada en autos, distinta por tanto al menos en sus aspectos material y formal de la impresa "acabada» por Rojas, solo se encuentra en las ediciones de la Comedia de Toledo 1500 y Sevilla 1501. Por consiguiente, la lectura de esta frase no fue accesible en los tiempos modernos hasta 1900, año en que el hispanista francés Foulché-Delbosc — que nunca creyó que Rojas fuera el genio creador de la Celestina- publicó la Comedia de Sevilla 1501. Pero como en las Comedias las rúbricas de la Carta y de los versos acrósticos atribuyen ambos textos al «autor» que en aquella hace referencia a estos considerándolos cosa propia, la deducción más lógica sería que el Bachiller Fernando de Rojas se refirió en dichas piezas preliminares a dos estados diferentes (manuscrito e impreso) de la obra que él "acabó». Así cuando Daniel Poyán publicó en 1961 la edición facsímil de la de Toledo 1500, se limitó a comentar en su Proscenio:

25.- Situación comprobada para Menéndez Pelayo y Menéndez Pidal, que colaboraron con Eugenio Krapf en su edición de 1899-1900 hecha sobre la de Valencia 1514. 
esta indicación de la cruz en el margen, no es posible más que en un texto manuscrito. Naturalmente no la encontramos en ninguna de las ediciones impresas. [...] Podemos deducir, pues, la proximidad de la edición de 1500 al manuscrito. (Poyán 1961: 11)

Aun entendiendo así las cosas, quedaba sin justificar la contradicción entre el anonimato de la Carta y la explicitud a este respecto de los versos acrósticos, lo que indujo a algún investigador a proponer soluciones basadas en tópicos prologales y tradiciones editoriales. Tal es, por ejemplo, el caso de Lida de Malkiel, quien escribe:

la declaración de "El auctor a un su amigo» no parece mentira del editor [...] antes bien coincide con una postura convencional que se propone rebajar modestamente el valor de la obra. Por modo análogo, el hecho de callar Fernando de Rojas su nombre y dejarlo asomar luego en el acróstico [...] es una práctica medieval frecuente en imitadores y refundidores para dar a conocer su incompleta autoría.(1962: 15)

Como vemos, Lida de Malkiel atribuye ambos paratextos a Fernando de Rojas, identificando al «auctor» de la Carta con el «autor» de los versos, y esto origina otra notable contradicción en sus palabras pues si ella considera que Rojas trata de "rebajar modestamente el valor de la obra», mal se compagina esta pretendida modestia con la alabanza de la obra entre exhortaciones:

teman grosseros y en obra tan alta o vean y callen, o no den enojos.

En resumen, los datos lingüísticos disponibles para interpretar los paratextos preliminares antes y después de la prohibición inquisitorial eran sustancialmente distintos, incluso contrapuestos, y no puede extrañar que también lo fueran las conclusiones extraídas de ellos: antes de tal prohibición Rojas sería conceptuado simplemente como componedor, adaptador, refundidor, editor, corrector o enmendador, y en los tiempos posteriores a ella lo ha sido como autor-creador.

Ya en los albores del siglo XXI, en algunas de las últimas ediciones de la Celestina va perdiendo protagonismo absoluto el nombre de Fernando de Rojas en la portada, como ocurre en la de Fernando Cantalapiedra (2000), en la de Lobera et alii (2000 y 2011) o en la de Bernaldo de Quirós (2010). Y José Luis Canet (2011) ha publicado la Comedia de Calisto y Melibea sin el nombre de Fernando de Rojas en la portada ni en la página del título, anónima, como se hacía originariamente. 
Paralelamente, son ya relativamente numerosas las propuestas de la crítica celestinesca actual que frente a las predominantes en los últimos años del siglo XIX y en el XX tienden a disminuir el papel de Rojas, tales como las de Cantalapiedra (1986, 2000, 2001 y 2011), Snow (1999-2000, 2001 y 2005-2006), García Valdecasas (2000), Di Camillo (2005 y 2010), Canet (2007 y 2011), Bernaldo de Quirós (2010), Paolini (2011) y algunos más entre los que nos incluimos nosotros con las publicaciones a que hemos aludido a lo largo de este artículo, si bien la intervención que cada uno le atribuye a Rojas en su "acabamiento" sea de mayor o menor envergadura, e incluso mínima, como Canet y Snow.

\section{Conclusión}

Como los diccionarios vienen a ser registro de las acepciones de sus voces en la época de su publicación, resultan imprescindibles para comprender exactamente lo que escritores de tiempos muy lejanos a los nuestros querían dar a conocer a través de sus palabras, y es necesario acudir a ellos para disminuir al máximo el riesgo de equivocarnos en su interpretación.

Nuestras consultas al Diccionario de Autoridades y testimonios de textos antiguos permiten asimilar AUTOR a editor, componedor, adaptador, refundidor o enmendador, a cuya luz cabe interpretar que sería precisamente esto lo que podrían entender los conocedores de la Celestina en los siglos XVI, XVII y XviII, siendo quizás esta la razón por la que no consideraron a Rojas autor-creador de los diálogos de la obra y la conceptuaron como anónima.

La cuestión no es entendida de esta manera por la mayoría de los críticos y analistas a partir del siglo XIX que interpretan el término AUTOR en su significado actual e identifican AUCTOR con AUTOR, si es que la edición o ediciones sobre las que trabajan no han eliminado las diferencias en las rúbricas de los paratextos preliminares.

Nosotros, desde la perspectiva que nos proporcionan los significados de las palabras analizadas en el presente estudio y otros trabajos anteriores, proponemos que Rojas «acabó» (compuso, refundió, dio la última mano, arregló) una comedia de final feliz, manuscrita y titulada ya "Comedia de Calisto y Melibea» cedida por el anónimo AUCTOR, "escribiendo" a partir de ella el manuscrito de otra obra que, aunque conservara el mismo título, tiene desenlace trágico y la sacó a luz a través de la imprenta. ${ }^{26}$

26.- Hemos analizado numerosas huellas de esta comedia de final feliz manuscrita y esbozado una aproximación a la trama argumental original en nuestro trabajo de 2017. 


\section{Bibliografía citada}

Adinolfi, Giulia (1954), "La Celestina e la sua unità di composizione», Filologia Romanza (Torino) I, 3, pp.12-60.

Alfonso X. Ver Campa GutiérRez, Mariano de la.

Amadís de Gaula. Los cuatro libros de Amadís de Gaula nuevamente impressos y hystoriados (1533), Venecia, Antonio de Sabia. (BNE sig. R.8494).

Andrés Martín, Melquíades (ed.) (1988), Carro de dos vidas, de Gómez García, Madrid, Universidad Pontificia de Salamanca, Fundación Universitaria.

Asensio, Manuel J. (1952), «El tiempo en La Celestina», Hispanic Review (Philadelphia) XX, pp. 28-43.

Avalle-Arce, Juan Bautista (1990), Amadís de Gaula: el primitivo y el de Montalvo, México, Fondo de Cultura Económica.

Ayllón, Cándido (1984), La perspectiva irónica de Fernando de Rojas, Madrid, Porrúa Turanzas.

AzÁcetA, José María (ed.) (1966), Cancionero de Juan Alfonso de Baena. Edición crítica, Madrid, Consejo Superior de Investigaciones Científicas, Clásicos Hispánicos, 3 vols.

Baena, Juan Alfonso (c. 1449). Ver AzÁceta, José María.

Bataillon, Marcel (1961), 'La Cèlestine' selon Fernando de Rojas, París, Didier.

Bernaldo de Quirós, José Antonio (ed.) (2010), Comedia de Calisto y Melibea. Hacia La Celestina anterior a Fernando de Rojas. Edición, introducción y notas, Madrid, Manuscritos.

Blanco-White, José María (1824), "La Celestina», en José María Blanco-White. Antología, ed. Vicente Llorens, Barcelona, Labor, 1971, pp. 181-211.

Bonilla y SAN MARTín, Adolfo (1904), "Algunas consideraciones acerca de la Tragicomedia de Calisto y Melibea y sus autores», en sus Anales de la literatura española publicados por Adolfo Bonilla y San Martin (años 19001904), Madrid, Viuda e Hijos de Tello, pp. 7-24.

BotTA, Patrizia (1999), "El texto de La Celestina en la edición de Valencia, 1514", en Tragicomedia de Calisto y Melibea (Valencia, Juan Joffre, 1514). Estudios y edición paleográfica y facsimilar, eds. Nicasio Salvador Miguel y Santiago López-Ríos, Valencia, Institució Alfons el Magnànim, vol. I, pp. 17-29.

Buigues, Jean-Marc (2003), "La sociedad de los autores», en Historia de la edición y de la lectura en España, 1472-1914, eds. Víctor Infantes, François Lopez y Jean-François Botrel, Madrid, Fundación Germán Sánchez Ruipérez, pp. 292-302.

Cacho Blecua, Juan Manuel (ed.) (2008), Garci Rodríguez de Montalvo, Amadís de Gaula, Madrid, Cátedra, Letras Hispánicas, 2 vols. 
CACHo Blecua, Juan Manuel y LaCarRa, María Jesús (2012). Entre oralidad y escritura. La Edad Media. Historia de la Literatura española dirigida por José-Carlos Mainer, Madrid, Crítica.

Campa Gutiérrez, Mariano de la (2009), La Estoria de España de Alfonso X. Edición y estudio de la Versión crítica desde Fruela II hasta la muerte de Fernando II, Málaga, Universidad de Málaga, Anejos de Analecta Malacitana LXXV.

Canet Vallés, José Luis (1999), "Alonso de Proaza», en Tragicomedia de Calisto y Melibea (Valencia, Juan Joffre, 1514). Estudios y edición paleográfica y facsimilar, eds. Nicasio Salvador Miguel y Santiago López-Ríos, Valencia, Institució Alfons el Magnànim, vol. I, pp. 31-38.

- (2007), «Celestina: 'sic et non'. ¿Libro escolar universitario?», Celestinesca 31, pp. 23-58.

- (ed.) (2011), Comedia de Calisto y Melibea. Edición crítica, introducción y notas. Valencia, Universitat de València, Textos Parnaseo.

- (2014), "A vueltas con las ediciones de la Comedia de Calisto y Melibea», en Texto, edición y público lector en los albores de la imprenta, eds. M. Haro Cortés, y J. L. Canet, Valencia, Universitat de València, pp. 53-82.

- (2017), "La edición burgalesa de la Comedia de Calisto y Melibea: ¿̨manipulación lucrativa de su fecha de impresión?», eHumanista 35 (en prensa).

CAnFora, Luciano (2002), Il copista come autore, Palermo, Sellerio edditore (collana "La memoria»).

Cantalapiedra Erostarbe, Fernando (1986), Lectura semiótico-formal de "La Celestina", Kassel, Reichenberger.

- (ed.) (2000), Anónimo / Fernando de Rojas. TragiComedia de Calisto y Melibea. Edición crítica, Kassel, Reichenberger.

- (2011), «Fue tanto breve quanto muy sutil. Los paratextos de La Celestina», eHumanista 19, pp. 20-78.

CAstillo, Hernando del (1514), Cancionero general de muchos y diversos auctores, Valencia, Jorge Costilla (Biblioteca Pública Episcopal de Barcelona: 860 Cas.).

-- Ver González Cuenca, Joaquín, y Rodríguez Moñino, Antonio.

Castro Guisasola, Florentino (1924), Observaciones sobre las fuentes literarias de "La Celestina", Madrid, Consejo Superior de Investigaciones Científicas, Anejo V de la Revista de Filología Española (Reimpreso en 1973).

Cejador y Frauca, Julio (ed.) (1913), Fernando de Rojas. La Celestina, con introducción y notas, Madrid, Espasa-Calpe, Clásicos castellanos, 2 vols.

Comedia de Calisto y Melibea (1500), Toledo, Pedro Hagenbach. Ver Poyán Díaz, Daniel.

Compagnon, Antoine (sin fecha), Qu'est-ce qu'un auteur? Cours d'Antoine Campagnon, Université de Paris IV-Sorbonne. UFR de Littérature française et comparée. Cours de licence LLM 316 F2. http://www.fabula. org/compagnon/auteur2.php. 
Covarrubias, Sebastián de [1616] (1979), Tesoro de la Lengua Castellana o Española, Madrid, Turner.

Criado de Val, Manuel (1955), Índice verbal de "La Celestina", Madrid, Consejo Superior de Investigaciones Científicas, Anejo LXIV de la Revista de Filología Española.

Davis, Ruth (1929), New Data on the Authorship of Act Iof the "Comedia de Calisto y Melibea», University of Iowa, Studies in Spanish Language and Literature.

Di Camillo, Ottavio (2005), "Consideraciones sobre La Celestina y las instituciones dramatúrgicas del humanismo en lengua vulgar», en La Celestina 1499-1999. Selected Papers from the International Congress in commemoration of the Quincentennial Anniversary of La Celestina New York, eds. Ottavio Di Camillo y John O' Neill, New York, pp. 53-75.

- (2010), «When and Where was the First Act of La Celestina composed? A reconsideration", en De ninguna cosa es alegre posesión sin compañia. Estudios celestinescos y medievales en honor del profesor Joseph Thomas Snow, coord. Devid Paolini, New York, Hispanic Seminary of Medieval Studies, pp. 91-157.

Du Cange, Charles du Fresne (1678), Glossarium ad Scriptores Mediae et Infimae Latinitatis, Niord, L. Fabre.

Flores, Juan de (c. 1495). Ver Parrilla García, Carmen.

Foulché-Delbosc, Raymond (ed.) (1900), Comedia de Calisto e Melibea. Único texto auténtico de la Celestina, Barcelona-Madrid, L' Avenç, Biblioteca Hispánica I, 1900.

GAGLIARDI, Donatella (2007),»La Celestina en el Índice: argumentos de una censura», Celestinesca 31, pp. 55-84.

Garci-Gómez, Miguel (1993), Tres autores en "La Celestina». Aplicación de la informática a los estudios literarios, Impredisur, Granada.

García Valdecasas, José Guillermo (2000), La adulteración de "La Celestina», Madrid, Castalia.

Gilman, Stephen (1974), "La Celestina»: arte y estructura, Madrid, Taurus.

Gómez García (1500). Ver Andrés Martín, Melquíades.

GonzÁlez Aguejas, Lorenzo (1894), "La Celestina. ¿Está completa según hoy la conocemos? Una traducción alemana de 1520. Pasajes nuevos que contiene», La España Moderna (Madrid) LXVII, pp. 78-103.

González Cuenca, Joaquín (ed.) (2004), Cancionero General de Hernando del Castillo, Madrid, Castalia, Nueva Biblioteca de Erudición y Crítica, 5 vols.

House R. E.; Mulroney, M.; Probst, I. G. (1924), «Notes on the Authorship of the Celestina", Philological Quarterly (Iowa) III, pp. 81-91.

InfanTES, Víctor (2010), La trama impresa de Celestina. Ediciones, libros y autógrafos de Fernando de Rojas, Madrid, Visor Libros.

Lida de Malkiel, María Rosa (1962), La originalidad artística de La Celestina, Buenos Aires, Eudeba. 
Lobera, Francisco J., Serés, Guillermo; Díaz-Mas, Paloma; Mota, Carlos; Ruiz Arzálluz, Íñigo; Rico, Francisco (eds.) (2000), Fernando de Rojas (y "antiguo autor»). La Celestina. Tragicomedia de Calisto y Melibea, Barcelona, Crítica. Reimpreso en 2011, Madrid, Real Academia Española, Biblioteca Clásica de la Real Academia Española.

Marciales, Miguel (ed.) (1985), Celestina. Tragicomedia de Calisto y Melibea. Fernando de Rojas. Al cuidado de Brian Dutton y Joseph T. Snow, Urbana and Chicago, University of Illinois Press, 2 vols.

McPheeters, D. W. (1961), El humanista español Alonso de Proaza, Madrid, Castalia.

Menéndez Pelayo, Marcelino (1895), Estudios de Crítica Literaria, Madrid. Integrado en Orígenes de la novela, III, 1961, $2^{a}$ edición, Madrid, Consejo Superior de Investigaciones Científicas, pp. 219-458

Menéndez Pidal, Ramón (1950), «La lengua en tiempo de los Reyes Católicos (Del retoricismo al humanismo)», Cuadernos Hispanoamericanos 13, pp. 9-24.

Miguel Martínez, Emilio de (1996), La Celestina de Rojas, Madrid, Gredos. NORTON, Frederick J. [1966] (1997), La imprenta en España. 1501-1520. Traducción de Daniel Martín Arguedas. Edición anotada por Julián Martín Abad. Madrid, Ollero \& Ramos Editores.

Oostendorp, H. Th. (1966), "La evolución semántica de las palabras españolas 'auctor' y 'actor' a la luz de la estética medieval», Bulletin Hispanique LXVIII, 3-4, pp. 338-352.

Paolini, Devid (2011), «Sobre un tópico equivocado (las representaciones de Plauto y Terencio en España a finales del siglo Xv) y Celestina», Celestinesca 35, pp. 67-84.

Parrilla García, Carmen (ed.) (1988), Juan de Flores. Grimalte y Gradisa, Santiago de Compostela, Universidad de Santiago.

Pedraza Gracia, Manuel José (2008), El libro español del Renacimiento. La "vida" del libro en las fuentes documentales contemporáneas, Madrid, Arco/ Libros, Instrumenta Bibliologica.

Pérez de NÁjera, Francisco (1604), Orthographia castellana dividida en primera y segunda parte a modo de Diálogo entre dos niños de la escuela, Valladolid, Luis Sánchez.

Poyán Díaz, Daniel (ed.) (1961), Comedia de Calisto y Melibea, Toledo 1500. Facsímile. Cologny-Genève, Bibliotheca Bodmeriana.

Prieto de la Iglesia, Remedios (2014), "Erratas y corrector de la impresión: Alonso de Proaza y Celestina», Celestinesca 38, pp. 113-124.

-y SÁnchez SÁnchez-Serrano, Antonio (2017), «Leyendo analíticamente la Celestina. Huellas en sus diálogos de la trama argumental de una comedia precedente», eHumanista 35 (en prensa).

-- Ver Sánchez Sánchez-Serrano, Antonio, y Prieto de la Iglesia, Remedios. 
Real Academia Española [1726-1739] (1976), Diccionario de Autoridades. Ed. facsímil. Madrid, Gredos, Biblioteca Románica Hispánica, 3 vols.

Real Academia Española [1770, 1780, 1783, 1791, 1803, 1869, 1884, 1899, etc.], Nuevo Tesoro Lexicográfico de la Lengua Española. http://buscon. rae.es/ntlle/SrvltGUIMenuNtlle?cmd=Lema\&sec=1.0.0.0

- (2001) Diccionario de la Lengua Española.

Riouer, Martín de (1957), "Fernando de Rojas y el primer acto de La Celestina», Revista de Filología Española XLI, pp. 373-395.

Rodríguez-Moñino, Antonio (ed.) (1958), Cancionero General recopilado por Hernando del Castillo (Valencia 1511). Edición facsímil por acuerdo de la Real Academia Española, con una introducción bibliográfica, indices y apéndices por Antonio Rodríguez-Moñino, Madrid, Real Academia Española.

Rubio García, Luis (1985), Estudios sobre La Celestina, Murcia, Universidad de Murcia, Departamento de Filología Románica.

Ruiz Ramón, Francisco (1974), "Notas sobre la autoría del Acto I de La Celestina», Hispanic Review XLII, pp. 431-435.

Russell, Peter E. (ed.) (2001), Fernando de Rojas. La Celestina. Comedia o Tragicomedia de Calisto y Melibea. Edición, introducción y notas, Madrid, Castalia.

Salvador Miguel, Nicasio (1991), "La autoría de La Celestina y la fama de Rojas», Epos VII, pp. 275-290.

- (1999), "Fernando de Rojas y La Celestina», en Tragicomedia de Calisto y Melibea (Valencia, Juan Joffre, 1514). Estudios y edición paleográfica y facsimilar, eds. Nicasio Salvador Miguel y Santiago López-Ríos, Valencia, Institució Alfons el Magnànim, vol. I, pp. 7-15.

Sánchez Sánchez-Serrano, Antonio [1985] (1988), Mensaje de La Celestina. Análisis de un proceso de comunicación diferida (Departamento de Lingüística y Literatura, Facultad de Ciencias de la Información), Madrid, Universidad Complutense, col. Tesis Doctorales. Premio Extraordinario 1984-85.

- (2014), "Las abreviaturas en cuatro ediciones tempranas de la Celestina: Toledo 1500, Burgos 1499-1502 (?), Zaragoza 1507 y Valencia 1514. Catalogación, cuantificación y consecuencias editoriales», Celestinesca 38, pp. 125-154.

- y Prieto De la Iglesia, Remedios (1989), "Fernando de Rojas acabó la Comedia de Calisto y Melibea», Revista de Literatura (Consejo Superior de Investigaciones Científicas) LI, 101, pp. 21-54

- (1991), Fernando de Rojas y La Celestina, Barcelona, Teide.

- (2009), "Sobre la ‘composición' de la Celestina y su anónimo 'auctor'», Celestinesca 33, pp. 143-171.

- (2011), "'Auctor', 'autor' y otros problemas semánticos concernientes a la autoría, gestación y ediciones de la Celestina», Celestinesca 35, pp. 85-136. 
Severin, Dorothy S. (ed.) (1989), Fernando de Rojas. La Celestina, Madrid, Cátedra.

Snow, Joseph T. (1997), "Hacia una historia de la recepción de Celestina: 1499-1822», Celestinesca 21, pp. 115-172.

- (1999-2000), «Fernando de Rojas, ‘autor de Celestina?», en Studia Hispanica Medievalia V. Actas de las VI Jornadas Internacionales de Literatura Española Medieval, eds. A. Liotta \& S. Lupi, Letras 40-41, Buenos Aires, Universidad Católica de Buenos Aires, pp. 152-157.

- (2001), «Los estudios celestinescos 1999-2099», en La Celestina. V Centenario (1499-1999), Actas del Congreso Internacional Salamanca, Talavera de la Reina, Toledo, La Puebla de Montalbán, 27 de septiembre a 1 de octubre de 1999, eds. Felipe B. Pedraza Jiménez, Rafael González Cañal y Gema Gómez Rubio, Cuenca, Universidad de Castilla-La Mancha, pp. 121-130.

- (2005-2006), «La problemática autoría de Celestina», Incipit 25-26, pp. 537-561.

Tragicomedia de Calisto y Melibea (1514), Valencia, Juan Joffre (Biblioteca Nacional de España: R/4870).

Tragicomedia de Calisto y Melibea (1514). Edición facsimilar, Madrid, Espasa-Calpe, 1975.

Tragicomedia de Calisto y Melibea (1514). Edición facsimilar, Barcelona, Círculo del Bibliófilo, 1977

Tragicomedia de Calisto y Melibea (Valencia, Juan Joffre, 1514). Edición facsimilar dirigida por Nicasio Salvador Miguel y Santiago López-Ríos, Valencia, Institució Anfons el Magnànim, 1999, 2 vols.

Tragicomedia de Calisto y Melibea (1518), Valencia, Juan Joffre (British Library: C.64.d.4).

Tragicomedia de Calisto y Melibea (1529), Valencia, Juan Viñao (British Library: C.63.f.25).

Valera, Juan (1900), "Nueva edición de 'La Celestina'», en Obras completas II, Madrid, Aguilar, 1949, pp. 1032-1036.

Valle Lersundi, Fernando del (1929), "Testamento de Fernando de Rojas, autor de La Celestina», Revista de Filología Española XVI (1929), pp. $366-$ 388.

Wolf, Fernando (1895), «Sobre el drama español: La Celestina y sus traducciones", La España Moderna (Madrid) LXXX, pp. 99-123. 


\title{
Prieto de la Iglesia, Remedios y Antonio Sánchez Sánchez- Serrano, «Posibles razones por las que la Celestina fue considerada anónima durante los siglos XVI-XVIII y creación de Rojas a partir del XIX», Celestinesca 40 (2016), pp. 135-158.
}

\section{RESUMEN}

La interpretación de los paratextos preliminares de la Celestina a la luz de las acepciones del Diccionario de Autoridades conduce a diferenciar entre un "auctor» anónimo para la Carta y un "autor» nombrado en el acróstico, y a identificar el antiguo término "auctor» con el actual cedente y "autor» con componedor, refundidor y editor. Como, además, la práctica editorial de los primeros tiempos de la imprenta permitía la utilización como propios de textos manuscritos ajenos y anónimos, es natural que en la época antigua no se considerase a Rojas autor-creador (inventor) de la Celestina y se conceptuara la obra de anónima. Frente a esto, los cambios en el plano lingüístico y en las circunstancias de la recepción operados en el siglo XIX propiciaron la corriente de opinión favorable a la autoría creativa de Rojas.

PALABRAS CLAVE: Celestina, auctor, autor, cedente, editor, refundir, componer.

\begin{abstract}
The interpretation of the paratexts of the Celestina in the light of the definitions of the Diccionario de Autoridades allows to differentiate between an anonymous «auctor» for the Carta and the "autor» identified in the acrostics, as well as to establish an equivalence between the old term "auctor» and the modern term "bestower", and "autor» with the modern "composer», "adapter», "editor». And because the editorial practices of 500 years ago allowed the reproduction of anonymous texts without any acknowledgement of authorship, it was only natural that originally Fernando de Rojas was not considered as the author (that is the creator) of the Celestina, and that this work was considered anonymous. Only the changes in words meaning and other circumstances related to the reception of the Celestina during the $19^{\text {th }}$ century gave rise to an opinion favorable to attribute to Rojas the authorship.
\end{abstract}

KEY WORDS: Celestina, auctor, author, bestower, editor, reworking, composition.

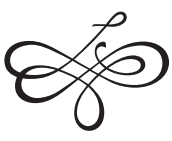

